\title{
Economizing the stability of rubble-mound breakwaters using artificial neural network
}

\author{
M. Shakeri Majd ${ }^{1}$, M. A. Lashteh Neshaei ${ }^{2} \&$ M. Salehi ${ }^{3}$ \\ ${ }^{I}$ Department of Civil Engineering, Islamic Azad University, \\ Anzali Unit, Iran \\ ${ }^{2}$ Department of Civil Engineering, Guilan University, Iran \\ ${ }^{3}$ Department of Civil Engineering, \\ Iran University of Science and Technology, Iran
}

\begin{abstract}
Economic design in different types of breakwaters has been a most important issue. Although advanced models exist, they are often based on two-dimensional simulations using plane-stress method. A new approach was used in three dimensional analyses, which is based on the finite element method to recognize the best stability of structure in rubble-mound breakwaters. Also the geometry of modeling was explored by artificial neural network to assess the validity of geometry. As a case study, the results of the $3 \mathrm{D}$ finite element method and artificial neural network are investigated by a Caspian Sea breakwater's data. The converge ratio of these methods are close to unity. The results show the good ability of artificial neural network in training and estimating the geometry of armor layer and the stability of rubble-mound breakwaters by a good accuracy.
\end{abstract}

Keywords: rubble mound breakwaters, geometry, artificial neural network economizing, marine transportation.

\section{Introduction}

Breakwaters are constructed to provide protection to the port and harbor facilities from dynamic forces of the ocean waves. The traditional and most commonly used breakwaters are of the rubble mound type which consists of one or two layers of armor stone, one or two filter layers and a core of quarry. The design of the breakwater section, which is normally of trapezoidal shape, is described in 
great detail in the US Shore Protection Manual [1]. The conventional breakwaters are designed in such a way that little or no damage is allowed to the structure. This criterion necessitates the use of large and heavy rock or artificial concrete units for armoring. A more economic section could be a structure with smaller armor unit, where profile development is being allowed in order to reach a stable profile. A single slope rubble mound breakwater subjected to waves undergoes some rearrangement of armor stones and gets stabilized to the "Sloppy - shaped profile". Many coastal engineers have proved that S-Shaped breakwaters are more stable than conventional breakwaters Priest et al. (1964), states that it would be practical to design such a section that would be stable for the design incident wave height but with smaller stones than would be required by conventional formula. Brunn and Johannesson (1976) described the hydraulics of S-shaped breakwater and recommended the use of S-shaped breakwater geometry, instead of continues single slope, for an increase in safety. and economy Aysen et al. (1989), conducted series of test stone three slopes composite rubble mound breakwater and concluded that under the same test condition (same wave height, period range, water depth, and armor stone) the three slope berm type section produce up to $90 \%$ less damage relative to the $1: 2$ single slope section. Also, the increase in wave height by 2.3 times the design wave height, the alternate section received damage ranging between $5 \%$ and $12 \%$. Earlier experiments done in the marine structures laboratory, NITK, Surathkal, on berm breakwaters have shown that an increase in berm width reduces the damage to a large extent and it is possible to reduce armor size by providing the berm, for the same wave parameters (Ming and Chiew [2]).

\section{The modeling}

For simulation of a sample breakwater the ADINA (K.J. Bathe) program was used. In the first step, the general geometry of breakwater modeling was generated. This breakwater is started from seaside and follows in straight line to wave's breaking zone. This breakwater started from sea shore (minimum depth$5 \mathrm{~m}$ ) to wave's breaking zone $25 \mathrm{~m}$ (maximum depth) in which $\mathrm{H}_{0}^{\prime}$ is effective height of wave in sea and $\mathrm{d}$ is depth of the breakwater and $\mathrm{H}_{\mathrm{f}}$ is freeboard exist. The maximum value for $\mathrm{H}^{\prime}{ }_{0}$ in all situations is $5 \mathrm{~m}$ and $\mathrm{d} / \mathrm{H}^{\prime}{ }_{0}$ (no dimensional parameter) is varied from 1 to 5 ; that explains the depth started from $5 \mathrm{~m}$ and gets $25 \mathrm{~m}$ (the depth at the end of the structure). We consider that the overflow for this structure is forbidden, which results in the minimum damage for breakwater structure. By this way, the parameter $\mathrm{H}_{\mathrm{f}} / \mathrm{H}_{0}^{\prime}$ is varied from 1 to 2.8 that mean $\mathrm{H}_{\mathrm{f}}$ is varied from $5 \mathrm{~m}$ to $14 \mathrm{~m}$. Only at the shoreline, in minimum depth, do the nodes have no degree of freedom. The different materials were specified for any layers. The clay was used in core layer, and the sand was used in filter layer, finally two different stones (smooth and rough) were used for the armor layer. The parameters which were presented adopted the simulation according to the critical-state theory. For a complete description of the stressstrain behavior of the soil according to the model, the following parameters are required: $\theta$ is the slope of the critical-state in the $e$ - $\ln p$ ' plane, where $e$ is void 
ratio and $p^{\prime}$ is the effective stress. In this state $p^{\prime}$ is equal to $1 \mathrm{KPa} . \mathrm{v}$ is the poisson coefficient; and $G$ is the shear modulus. The nodes were applied prescribed displacements for static analysis and apply modal stress to provide control of input data's calculation. To define the stress history and yield surface, the model requires insitu stresses and maximum over consolidation stress.

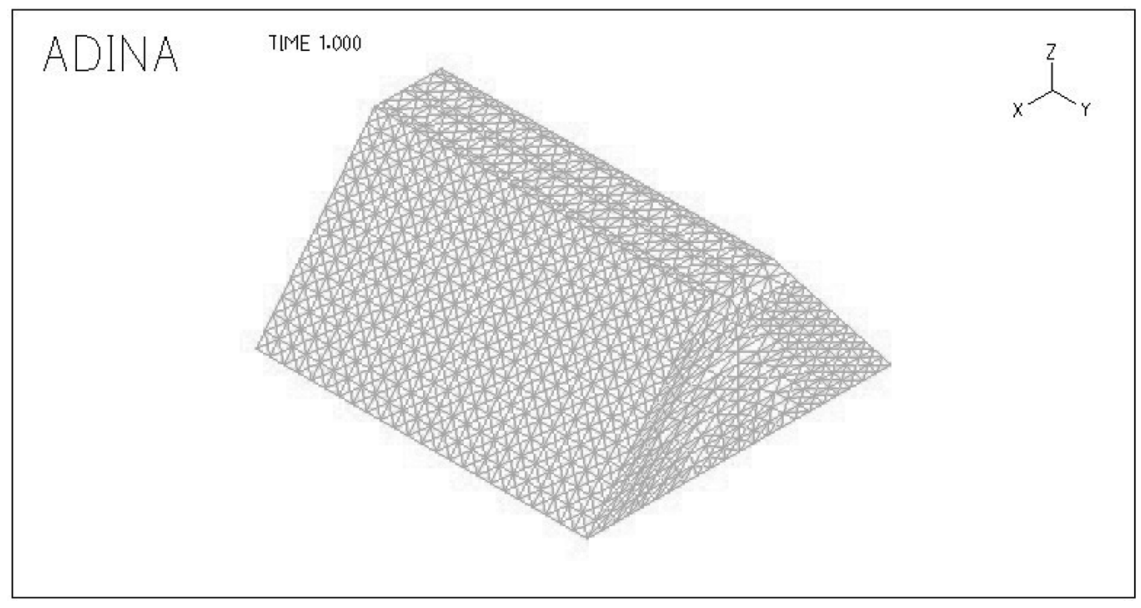

Figure 1: $\quad$ Finite element method geometry of breakwater.

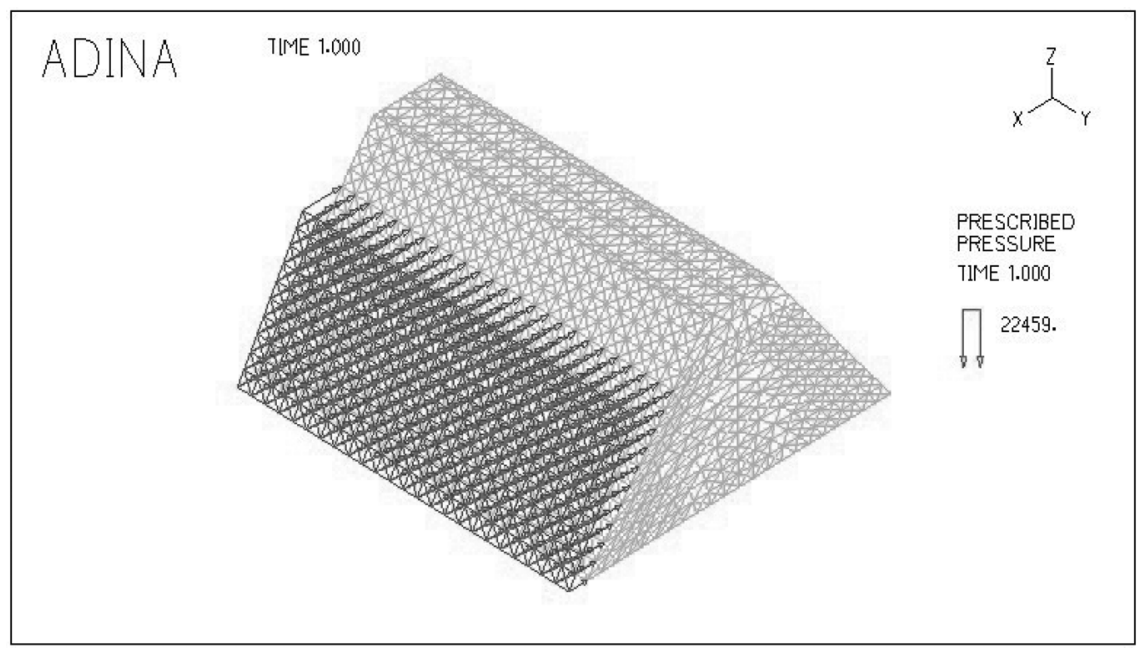

Figure 2: $\quad$ Model of force loading.

The breakwater region shows an artesian pressure at the base of the clay layer, which causes an upward flow of fresh water, reducing the in situ effective stresses and causing leaching of Cam-Clay layer that was defined by the effect of 
earth pressure. Where the construction was assumed to be undrained $(v \approx 0.5)$ and the long-term condition drained $(v \approx 0.3)$, these hypotheses led to unsatisfactory predictions in terms of horizontal deformations. The studies, in fact, indicated that long-term horizontal displacements $\left(\delta_{\mathrm{h}}\right)$ should be smaller than at the end of the construction, contrary to field observations. For some time it was acceptable as a principle that the increase observed in $\delta_{\mathrm{h}}$ after loading completion was due only to undrained creep and soil anisotropy, these phenomena being use to explain many of the erroneous simulations in elastic studies. According to this method, three main situations (minimum, medium and maximum depth) of breakwater were assumed and in this situation based on depth of water, from minimum to maximum depth, the finite element simulation of breakwater section is shown which is made by three layers of armor, filter and core, fig. 1. In each layer, the property of materials should be described. In fig. 2, wave forces are loaded on the breakwater face. The damage is described by the amount of armor rock fill displacement in horizontal and vertical (local or global) axes. Finally, the amount of stress ratio in elements must be evaluated. The mobilized undrained strength depends on the mode of loading, with typical values of undrained strength, Shakeri Majd and Lashteh Neshaie [3].

\section{The artificial neural network modeling}

In many engineering problems, there is not a good reliability between input and output data. Obviously it is very hard to decrease the errors, because usually an advanced technology should be applied to perform a high-precision measurement. However, man-made errors and environmental errors could little be prevented, .so it is of importance to employ methods which can prevent these errors and shortcoming. Instead of numerical methods applicable in complicated engineering problems, application of powerful databases and theoreticalpractical methods are nowadays is widely considered. Because such problems are sometimes such complicated that no one could apply a close solution to solve them. The above-mentioned new methods are involved artificial neural network (ANN) algorithms. The use of ANNs will soon have a great role in engineering practices. Physically all ANNs relate sets of simple mathematical operations. Each of these calculation units has a limited local memory that operates basic mathematical operations on input data. The power of ANNs is from the combination of parallel parts of them. It means that the input data can be processed synchronically. The structural form of ANNs consists of a lot of linked-to-each-other neural processing units. These artificial neurons hold a portion of information or only have the ability to do some simple calculations. Each of them provides data from the neighbor part, does the own operation on it and calculates the output, then transports to the other neighbor part. The pattern of relations between processing units and strength of connections loads to save the network information as some codes. In the mentioned software a multi layer prosper on net (MLP) and a back training algorithm (Back Propagation) is used, where the used bank is two sets of data called smooth stone and rough stone. 


\subsection{Rough stone ANN modeling}

According the results obtained from the simulation of the construction used ADINA software (K.J. Bathe) that performed 190 useful data. 159 input data Among 190 were selected to network training and 31 data were used to final test. Since the program uses a nonlinear sigmoid activation function $\left(\operatorname{sig}(x)=1 / 1+e^{-x}\right)$ in the hidden layer and output layer, that is a suitable activation function in solving engineering problems and it is no reason to use more than one hidden layer except in uncertain cases, so all trial and errors are performed in determination of number of neurons in hidden layer.

The used ANN has two hidden layers; the hidden layer 1 has 20 neurons and hidden layer 2 has 9 neurons. These optimum numbers of neurons were obtained based on trial and error. The end-of-operation criterion was an average error of less than 0.001 . The rate of training and the amount of momentum were considered as 0.6 and 0.8 respectively. The schematic architectural view of network is shown in fig. 3 that presents the graphic future of the network layers, biases, values of errors and etc. Figure 4 shows the diagram of maximum and minimum of errors versus the number of cycle.

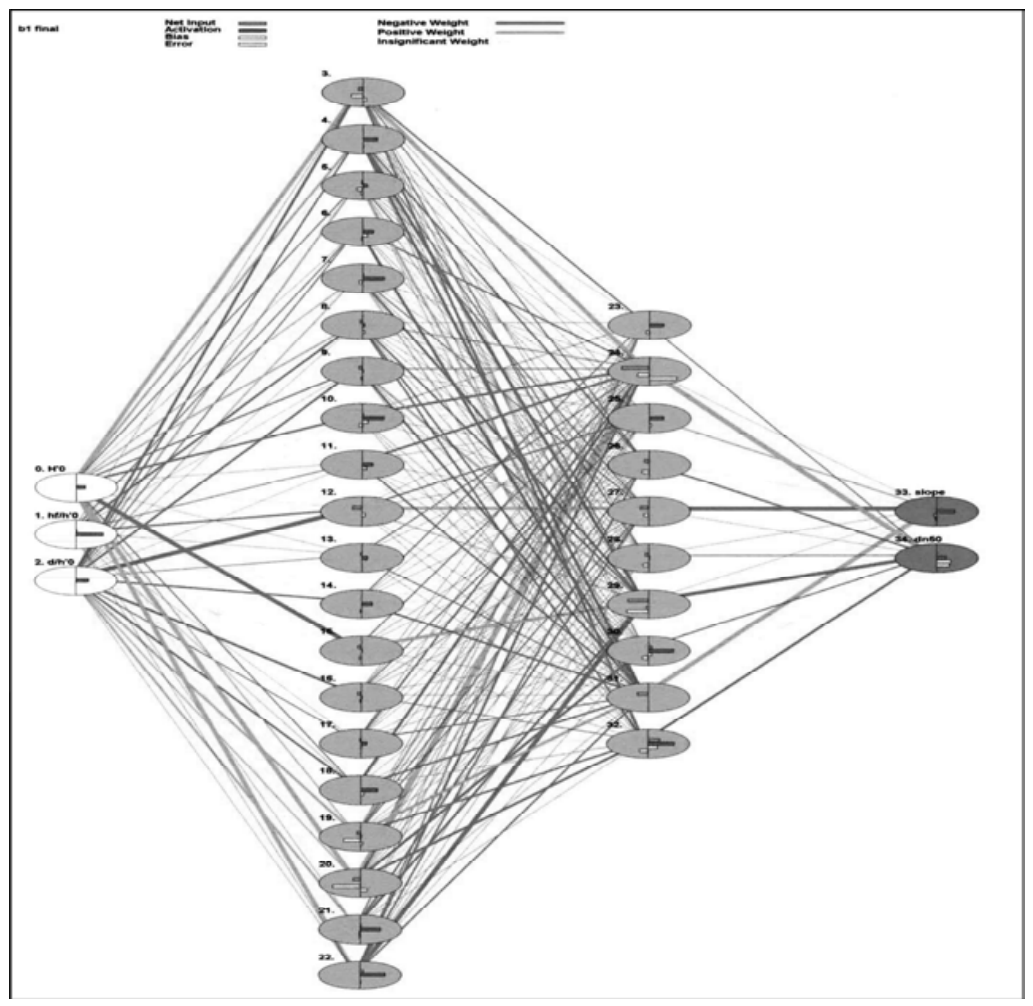

Figure 3: The schematic architectural view of rough stone network. 
52 Fluid Structure Interaction and Moving Boundary Problems IV

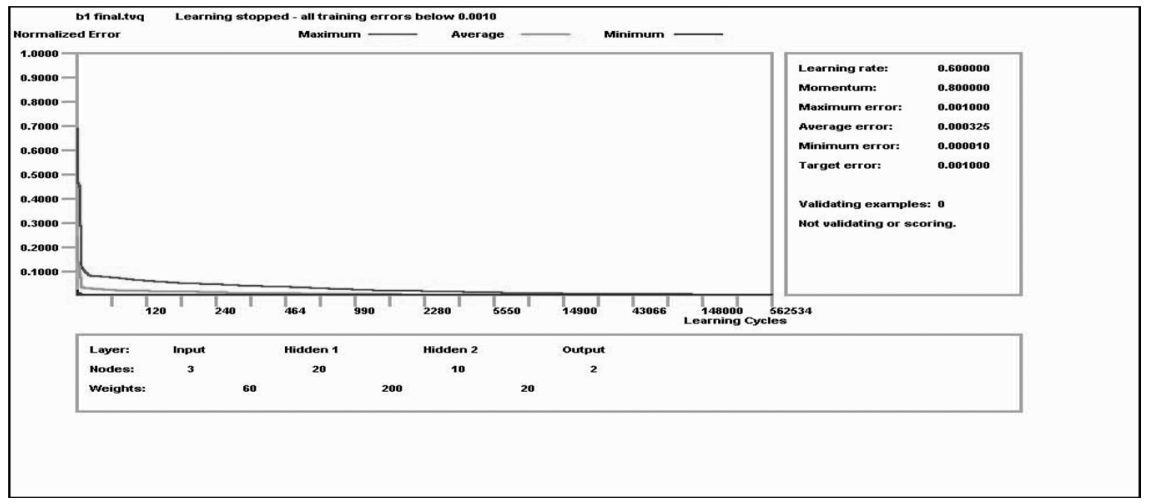

Figure 4: The diagram of maximum and minimum of errors for rough stone.

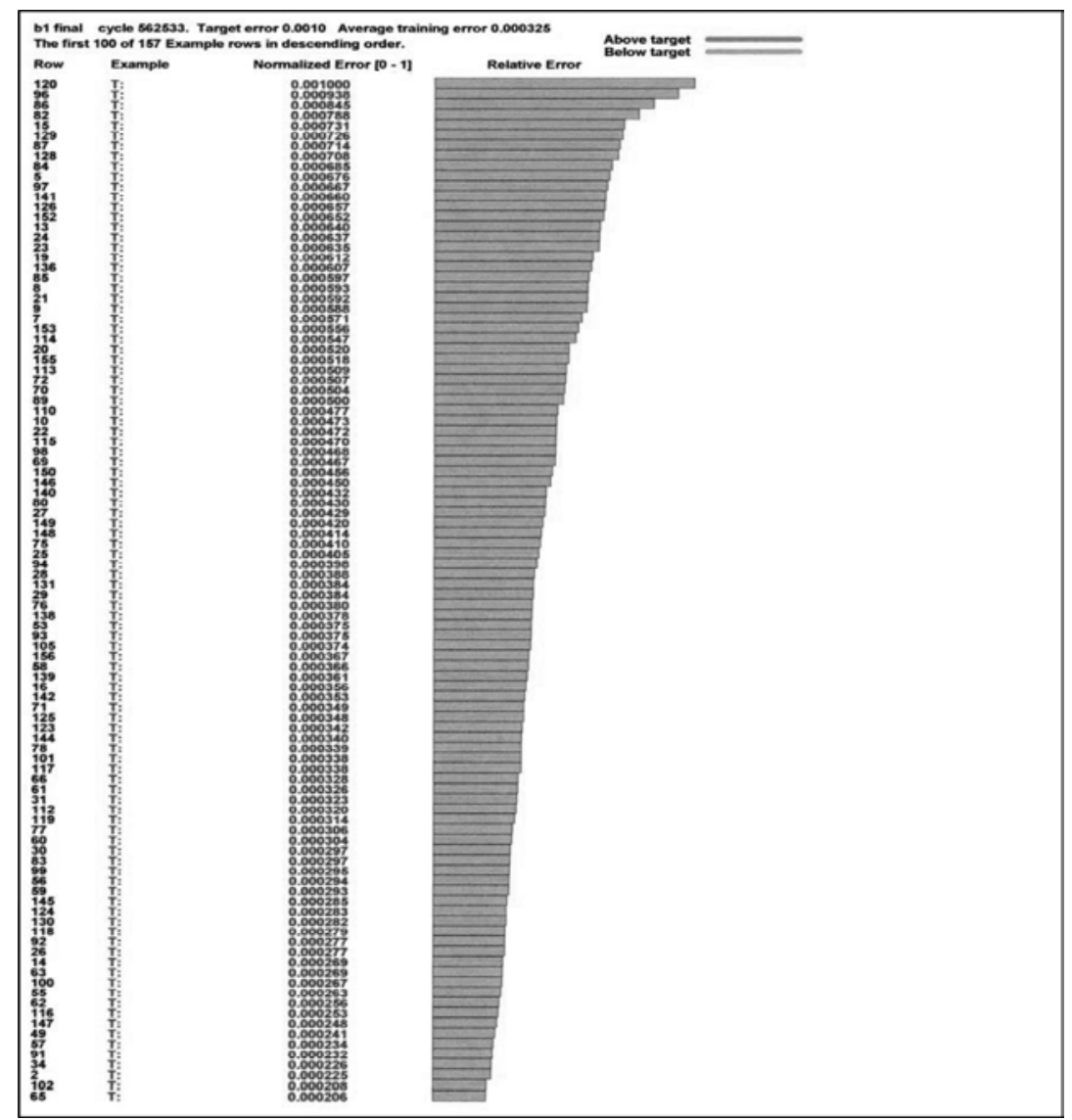

Figure 5: Relative errors of rough stone. 
After reliable training results of geometry and equilibrium situation for local properties based on Hudson formula and Irribaren formula, shown in table 1, were used for the evaluation of the ANN model. The values of obtained from calculated by model, are presented in table 1 that also contains the relative error based on ANN model. It can be seen the relative error values are always below $10 \%$.

Table 1: $\quad$ Samples for rough stone relative errors of output data.

\begin{tabular}{|l|c|c|c|c|c|c|c|c|c|}
\hline \multicolumn{9}{|c|}{ Input } & \multicolumn{5}{l|}{ Output } \\
\hline \multicolumn{3}{|l|}{ Data } & \multicolumn{1}{|l|}{ Data } & \multicolumn{3}{l|}{ Error percent } \\
\hline $\mathrm{No}$ & $\mathrm{H}_{0}^{\prime}$ & $\mathrm{h}_{\mathrm{f}} / \mathrm{h}_{0}^{\prime}$ & $\mathrm{d} / \mathrm{h}_{0}^{\prime}$ & Slope & $\mathrm{d}_{\mathrm{n} 50}$ & Slope & $\mathrm{d}_{\mathrm{n} 50}$ & Slope & $\mathrm{d}_{\mathrm{n} 50}$ \\
\hline 1 & 9.5 & 1 & 2 & 48 & 3.755 & 48.01 & 3.750 & 0.01 & 0.14 \\
\hline 2 & 9.5 & 1 & 5 & 61 & 4.414 & 60.98 & 4.460 & 0.03 & 1.04 \\
\hline
\end{tabular}

b1 final.tvq 562534 cycles. Target error 0.0010 Average training error 0.000325

The first 3 of 3 Inputs in descending order.

\begin{tabular}{llcc|} 
Column & Input Name & Importance & Relative Importance \\
0 & $\mathrm{H}^{\prime} 0$ & 59.7823 & \\
2 & $\mathrm{~d} / h^{\prime} 0$ & 56.8227 & \\
1 & $\mathrm{~h}^{\prime} \mathrm{h}^{\prime} \mathrm{O}$ & 17.1234 & \\
\hline
\end{tabular}

Figure 6: Relative importance of rough stone.

b1 final.tvq 562534 cycles. Target error 0.0010 Average training error 0.000325

The first 3 of 3 inputs in descending order.

$\begin{array}{llrccl}\text { Column } & \text { Input Name } & \text { Change from } & \text { to } & \text { Sensitivity } & \text { Relative Sensistivity } \\ 2 & \mathrm{~d} / h^{\prime} 0 & 1.0000 & 5.0000 & 0.54869943 & \\ 0 & \mathrm{H}^{\prime} 0 & 1.0000 & 10.0000 & 0.47488649 & \\ 1 & \text { hff'h } & 1.0000 & 1.5000 & 0.05212625 & \end{array}$

Figure 7: Relative sensitivity of rough stone.

Maximum relative error for output data is $8.84 \%$ for the 3 rd row and the last relative errors are below $4 \%$ and target error is 0.001 . With addition to relative errors for input data fig. 5 and output data and target error we can say that the ANN model can predict the angel of armor layer of breakwater for smooth stone. Relative importance and relative sensitivity histograms of input data show the relative importance and relative sensitivity of each Input columns. Relative 
importance graph can show the relative importance of the relevant parameters. $\mathrm{H}_{0}^{\prime}$ is more importance than the other input data, fig. 6 and the relative sensitivity graph can show the relative sensitivity of parameters that ranks them (fig. 7).

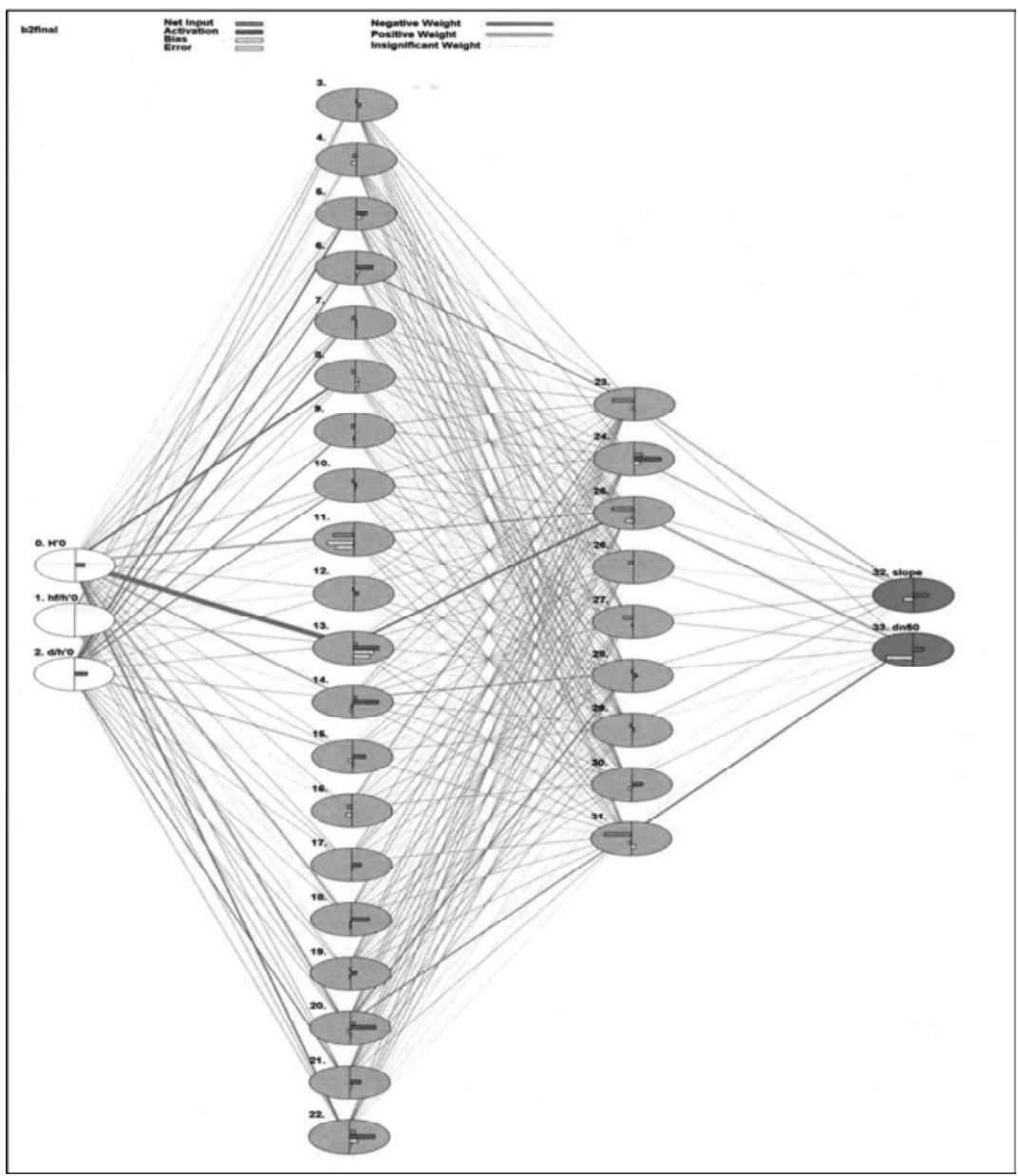

Figure 8: The schematic architectural view of smooth stone network.

\subsection{Smooth stone ANN modeling}

Like smooth stone modeling we uses a nonlinear sigmoid activation function in hidden layer. The used ANN has two hidden layers; hidden layer 1 has 20 neurons and hidden layer 2 has 10 neurons. These optimum numbers of neurons were obtained based on trial and error. The end-of-operation criterion was an average error of less than 0.001 . The rate of training and the amount of momentum were considered as 0.6 and 0.8 , respectively. The schematic architectural view of network is shown in fig. 8 that that presents the graphic 
future of the network layers, biases, values of errors and etc. fig. 9 shows the diagram of maximum and minimum of errors versus the number of cycle.

After reliable training results of geometry and equilibrium situation for local properties based on Hudson formula and Irribaren formula, shown in table 2, were used for evaluation of ANN model.

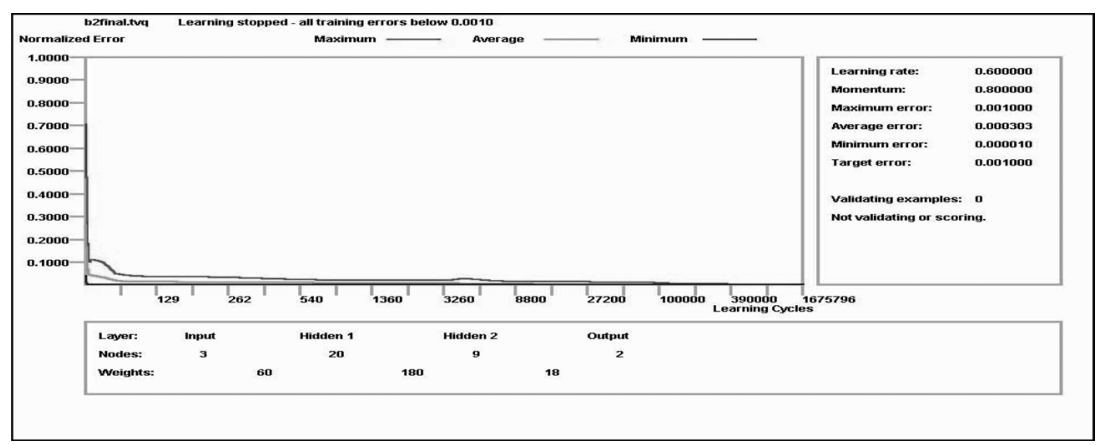

Figure 9: The diagram of maximum and minimum of errors for smooth stone.

Table 2: $\quad$ Samples for smooth stone relative errors of output data.

\begin{tabular}{|c|c|c|c|c|c|c|c|c|c|}
\hline \multicolumn{5}{|c|}{ Input } & \multicolumn{5}{c|}{ Output } \\
\hline No & $\mathrm{H}_{0}^{\prime}$ & $\mathrm{h}_{\mathrm{f}} / \mathrm{h}_{0}^{\prime}$ & $\mathrm{d} / \mathrm{h}_{0}^{\prime}$ & Slope & $\mathrm{d}_{\mathrm{n} 50}$ & Slope & $\mathrm{d}_{\mathrm{n} 50}$ & Slope & $\mathrm{d}_{\mathrm{n} 50}$ \\
\hline 1 & 9.5 & 1 & 4 & 55 & 4.841 & 54.99 & 4.836 & 0.02 & 0.11 \\
\hline 2 & 9.5 & 1 & 5 & 58 & 5.029 & 57.99 & 5.018 & 0.02 & 0.21 \\
\hline
\end{tabular}

It can be seen that the relative error values are always below $10 \%$. Maximum relative error is $9.7 \%$ for first row and the last relative errors are below $6 \%$ and target error is 0.001 . So we can say that the ANN model can predict the angel of armor layer of breakwater for rough stone. With addition to relative errors for input data fig. 10 and output data and target error we can say that the ANN model can predict the angel of armor layer of breakwater for smooth stone. Relative importance and relative sensitivity histograms of input data show the relative importance and relative sensitivity of each Input columns. Relative importance graph can show the relative importance of parameters that ranks them. $\mathrm{H}_{0}^{\prime}$ is more importance than the other input data, fig. 11 and the relative sensitivity graph can show the relative sensitivity of parameters that ranks them, fig. 12 . 
56 Fluid Structure Interaction and Moving Boundary Problems IV

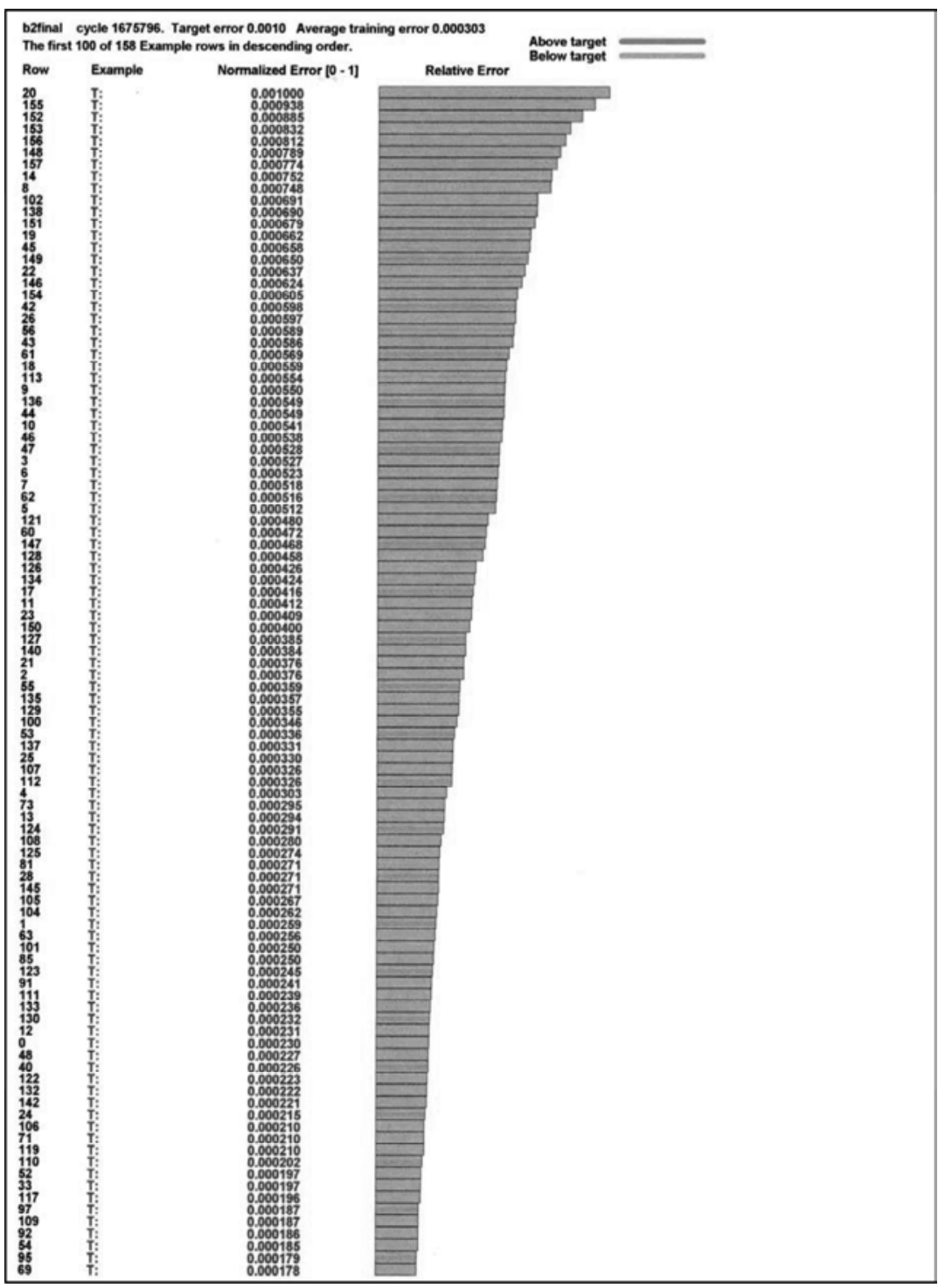

Figure 10: Relative errors of smooth stone. 


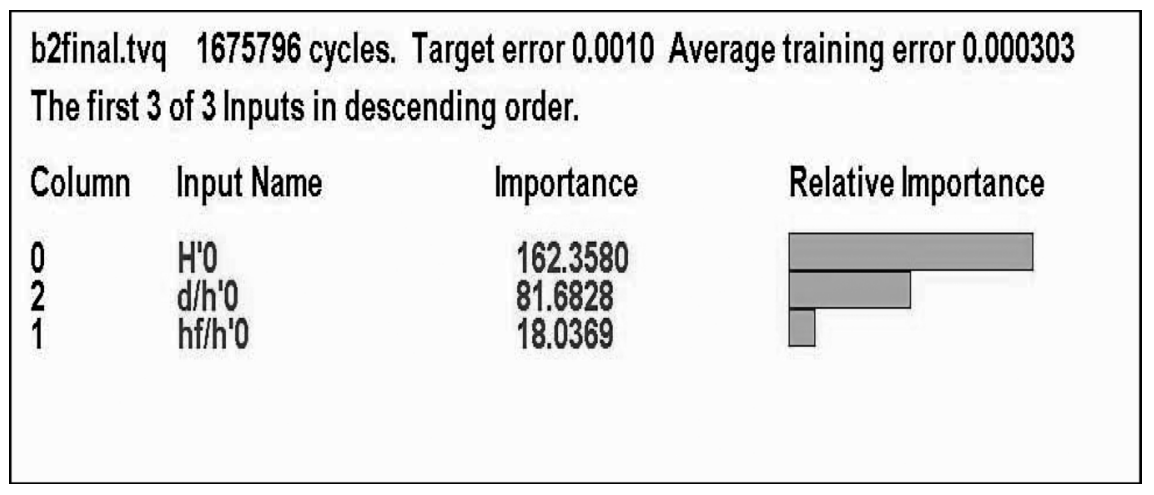

Figure 11: $\quad$ Relative importance smooth stone.

\begin{tabular}{|c|c|c|c|c|c|}
\hline \multicolumn{6}{|c|}{ b2final.tvq 1675796 cycles. Target error 0.0} \\
\hline \multicolumn{6}{|c|}{ The first 3 of 3 Inputs in descending order. } \\
\hline Column & Input Name & Change from & to & Sensitivity & Relative Sensistivity \\
\hline 2 & $d / h^{\prime} 0$ & 1.0000 & 5.0000 & 0.55380280 & \\
\hline 0 & $\mathrm{H}^{\prime \prime O}$ & 1.0000 & 10.0000 & 0.45643956 & \\
\hline & hifh'o & 1.0000 & 1.5000 & 0.05276132 & $\square$ \\
\hline
\end{tabular}

Figure 12: Relative sensitivity of smooth stone.

\section{Conclusion}

In this step we must compare between the results obtained from the two methods. We use the same input data for both methods. We assume $\mathrm{H}_{0}^{\prime}=5 \mathrm{~m}$, $\mathrm{h}_{\mathrm{f}} / \mathrm{h}_{0}^{\prime}=1.1, \mathrm{~h}_{\mathrm{f}} / \mathrm{h}_{0}^{\prime}=1.3, \mathrm{~d} / \mathrm{h}_{0}^{\prime}$ varied from 1 to 5 . These parameters are taken from the Caspian Sea. Our trying for the maximum and minimum errors for all stone in output estimating was less than 0.001. By increasing the cycle of calculating and more education, the errors were reduced. In fact, in our education two hidden layers and one input layer and one output layer was exist 15 model with different neuron and layer was tested to get this relative importance and errors our education was corrected. Our output from linear regret ion is close to the prediction from the neural network. The difference created by two algorithms that was used. Relative importance and relative sensitivity histograms of the input data show the relative importance and relative sensitivity of each Input columns. A relative importance histogram shows the importance and the relative importance of each Input column. The importance is the sum of absolute weights 
of the connections from the input layer to the first hidden layer. For this data the graph can show the relative importance of parameters that ranks them. $\mathrm{H}_{0}^{\prime}$ is more important than the other input data, see fig. 6 and fig. 11. Input importance is not the same as sensitivity analysis. Input importance is a measure of how each input will influence the next layer in the network. Sensitivity analysis is a measure of how the outputs change when the inputs are changed. This view shows how much the outputs change when the inputs are changed. The inputs are all set to the median values and then each in turn is increased from the lowest value to the highest value. The change in the outputs is measured as each input is increased from lowest to highest to establish the sensitivity to change. For this data the relative sensitivity graph can show the relative sensitivity of parameters that ranks them, fig. 7 and fig. 12. The ratio of outputs that achieved from F.E.M and ANN is near by one.

1. The sensitivity of model related by $\mathrm{d} / \mathrm{h}_{0}^{\prime}$. Our ranking for sensitivity is $\mathrm{d} / \mathrm{h}_{0}^{\prime}$, $\mathrm{H}_{0}^{\prime}, \mathrm{h}_{\mathrm{f}} / \mathrm{h}_{0}^{\prime}$.

2. Coefficient of relativity is related by $\mathrm{H}_{0}^{\prime}$.

3. The relative importance has following ranking; $\mathrm{H}_{0}^{\prime}, \mathrm{d} / \mathrm{h}_{0}^{\prime}, \mathrm{h}_{\mathrm{f}} / \mathrm{h}_{0}^{\prime}$.

4. by this studied we notice that the $h_{f}$ (the freeboard height) is not very importance about stability of structure.

5. By increasing the roughness the angel of stability and the weight of armor element could reduced.

6. By increasing the depth the angel of stability for armor layer was increased. This is may caused by the wave pressure that exist in datum level. This is explain that the cur vial surface in breakwaters cause to a good resistance against the wave pressure. we can use the output data regret ion equation in designing of the breakwaters.

\section{References}

[1] Shore Protection Manual, U.S. Army Coastal Engineering Research Center U.S. Government Printing Office, Washington DC, 1984.

[2] Ming, D. and Chiew, Y.M., Shoreline changes Behind Detached Breakwaters. Journal of waterway, Ports, Coastal and Ocean Engineering, ASCE 126 Vol. 2, pp.63-70, 2000.

[3] Shakeri Majd, M. and Lashteh Neshaie, M.A., Optimum Design of RubbleMound Breakwaters, proceeding of $7^{\text {th }}$ Civil Engineering Conference, Tarbiat Modarees University, Iran , May 2006 